\title{
Estimation of intestinal digestibility of undegraded sunflower meal protein from nylon bag measurements. A mathematical model
}

\author{
Javier González*, Leonardo Sánchez**, María Remedios Alvir \\ Departamento de Producción Animal, Escuela Técnica Superior de Ingenieros Agrónomos, \\ Universidad Politécnica de Madrid, 28040 Madrid, Spain
}

(Received 1 March 1999; accepted 20 September 1999)

\begin{abstract}
Ruminal nitrogen degradation and intestinal digestibility (ID) of the undegraded nitrogen of three sunflower meals were determined on three wethers fitted with rumen cannulae and T-type duodenal cannulae using nylon bags. Meals were obtained from semi-dehulled seeds by conventional hexane extraction (samples SD1 and SD2) or from whole seeds by a discontinuous procedure of pressing and hexane extraction (sample W), which causes a superior thermal effect. Therefore, effective degradability of nitrogen for the $\mathrm{W}$ sample $(0.537)$ was lower $(P<0.001)$ than for conventional meals. Between the latter, SD2 had a lower value $(P=0.019)$ than SD1 $(0.776$ and 0.812 , respectively). ID decreased in all meals $(P<0.001)$ as the ruminal incubation time $(t)$ increased. This evolution could be described accurately by an exponential curve as $\mathrm{ID}=s+h \mathrm{e}^{-k i}$. A method is proposed for estimating the proportion of undegraded ruminal nitrogen digested in the intestines $\left(D_{i}\right)$ from 1$)$ the above equation, 2) the undegradable $(r)$ and the insoluble and potentially degradable $(b)$ nitrogen contents of the feed and the degradation rate of the last fraction $\left(k_{d}\right)$, and 3$)$ the rumen outflow rate of particles $\left(k_{p}\right)$. The $D_{i}$ value is shown to be:

$$
D_{i}=s\left(r+\frac{b k_{p}}{k_{d}+k_{p}}\right)+h k_{p}\left(\frac{r}{k_{p}+k_{i}}+\frac{b}{k_{d}+k_{p}+k_{i}}\right)
$$

The percentages of nitrogen from digested feed in the intestines obtained with this method were 15.1, 17.2 and 39.0 for SD1, SD2 and W, respectively. Resulting effective ID values of undegraded nitrogen were $0.804,0.767$ and 0.844 . Undigested nitrogen after ruminal and intestinal incubations decreased in linear and quadratic form in all meals as ruminal incubation time increased. (C) Inra/ Elsevier, Paris
\end{abstract}

rumen degradation / undegraded protein / intestinal digestibility / mathematical estimation / sunflower meal

\footnotetext{
* Correspondence and reprints

E-mail: jgonzalez@pan.etsia.upm.es

** Present adress: CORPOICA-TIBAITATA, Las Palmas, Bogotá, Colombia
} 
Résumé - Estimation avec sachets de nylon de la digestibilité dans l'intestin des matières azotées du tourteau de tournesol. Proposition d'une méthode mathématique. La degradabilité de l'azote dans le rumen et la digestibilité dans l'intestin de l'azote non dégradé de trois tourteaux de tournesol ont été mesurées en sachets de nylon sur trois moutons munis d'une canule du rumen et du duodénum. Les tourteaux ont été obtenus par extraction conventionnelle à l'hexane à partir de graines semidécortiquées (échantillons SD1 et SD2) ou bien par un procédé discontinu de pression et extraction à l'hexane sur graines entières (échantillon W), qui produit un plus grand effet thermique. En conséquence, la dégradabilité de l'azote pour l'échantillon $\mathrm{W}(0,537)$ a été plus faible $(p<0,001)$ que pour les tourteaux conventionnels. Parmi ceux-ci SD2 a montré une valeur plus faible $(p=0,019)$ que SD1 $(0,776$ et 0,812 , respectivement). L'augmentation du temps de séjour dans le rumen $(t)$ a entraîné pour tous les tourteaux une diminution $(p<0,001)$ de la digestibilité dans l'intestin (ID), qui a pu être convenablement décrite par une courbe exponentielle : ID $=s+h \mathrm{e}^{-k i t}$. Une méthode pour établir la proportion d'azote non degradé digeré dans l'intestin $\left(D_{i}\right)$ a été développée à partir : 1) de l'équation précédente, 2) des proportions dans l'aliment d'azote potentiellement dégradable ( $b$ ) et indégradable $(r)$, et du taux de degradation $\left(k_{d}\right)$ de la fraction $b$ et iii) du taux de sortie de particules du rumen $\left(k_{p}\right) . D_{i}$ est alors égale à :

$$
D_{i}=s\left(r+\frac{b k_{p}}{k_{d}+k_{p}}\right)+h k_{p}\left(\frac{r}{k_{p}+k_{i}}+\frac{b}{k_{d}+k_{p}+k_{i}}\right)
$$

Le pourcentage d'azote de l'aliment digéré dans l'intestin determiné avec cette méhode a été de $15,1,17,2$ et 39,0 pour SD1, SD2 et W, respectivement. Les valeurs correspondantes de la digestibilité intestinale de l'azote non degradé dans le rumen ont été de $0,804,0,767$ et 0,844 . L'azote non digeré dans le rumen et l'intestin a montré une diminution linéaire et quadratique en fonction du temps de séjour dans le rumen. (C) Inra/Elsevier, Paris

dégradabilité rumen / azote non dégradé / digestibilité intestinale / estimation mathématique / tourteau de tournesol

\section{INTRODUCTION}

The application of new systems for the evaluation of protein in ruminants should be based on suitable estimations of both ruminal nitrogen degradability and intestinal digestibility (ID) of the undegraded nitrogen of feedstuffs. The values of ruminal nitrogen degradability of feeds are commonly obtained by the $\emptyset$ rskov and McDonald [17] procedure, based on nylon bag incubation and rumen passage rate data. The nylon bag technique has also been used to obtain estimations of ID of undegraded nitrogen [12, 25]. In comparison with other methods used to estimate intestinal digestibility, the mobile nylon bag technique has the advantages of 1 ) its adaptability which allows it to be used in systematic studies with a large number of feeds and 2) its relative simplicity. The technique may be simplified even more by doing away with the incubation in the abomasum, as suggested by Yang and Poncet [28], after verifying with different forages and concentrates that this incubation does not have any effect on the quantity of total nitrogen that has disappeared up to the ileum. Similarly, in other studies $[4,23]$ it was observed that pepsin- $\mathrm{HCl}$ preincubation does not affect the values of intestinal nitrogen digestion. Likewise, the small difference observed in concentrates for the nitrogen disappearance in bags recovered from the terminal ileum or from the faeces $[12,22,28]$ justifies the simplication of this technique without creating an important error. Assays with mobile nylon bags are, however, scarce and a greater effort is still needed to determine the possible factors that can affect this determination before the method can be used routinely for testing digestibility. Among these factors, the incubation time of the feed in the rumen is important, because the ID of 
different feeds can be affected by the time spent in the rumen and the associated degrading effects $[7,19,26,28]$.

The aims of this work were 1) to determine the effects of the time spent by feed particles in the rumen on ID of undegraded nitrogen with three different sunflower meals, and 2) to establish a dynamical model for the estimation of the effective value of ID.

\section{MATERIALS AND METHODS}

\subsection{Protein sources}

Two meals (SD1, SD2) from semi-dehulled sunflower seeds obtained from the same company and extracted by a conventional hexane extraction method were used. Another type of meal (W) obtained from whole sunflower seeds and with another origin was also used. Meal W was obtained by a discontinuous procedure of pressing and hexane extraction, with storage in great piles between both processes, which extended the period of time in which the material was exposed to the high temperatures resulting from the pressure process. All samples were ground with a blade mill (Retsch Ultracentrifugal ZM1; F. Kurt Retsch Gmbh \& Co., Haan, Germany) through a 2-mm screen for nylon bag assays and through a $1-\mathrm{mm}$ screen for chemical composition analyses (table I).

Table I. Chemical composition (percentage of dry matter) of sunflower meal samples.

\begin{tabular}{lccc}
\hline & SD1 & SD2 & W \\
\hline Organic matter & 93.0 & 91.4 & 93.4 \\
Ether extract & 1.53 & 1.73 & 0.96 \\
Crude protein & 39.4 & 37.8 & 34.9 \\
Neutral detergent fibre & 32.2 & 38.2 & 50.3 \\
Acid detergent fibre & 23.1 & 27.7 & 31.5 \\
Acid detergent lignin & 6.84 & 9.22 & 13.2 \\
NDIN $^{\mathrm{a}}$ & 5.07 & 9.38 & 25.7 \\
ADIN & 2.60 & 3.67 & 6.02 \\
\hline
\end{tabular}

NDIN: neutral detergent insoluble nitrogen; ADIN: acid detergent insoluble nitrogen.

a Percentage of total nitrogen.

\subsection{Animals and feeding}

Three wethers fitted with rumen cannulas and $T$ duodenal simple cannulas were used for all the trials. The animals were housed in metabolism cages and fed a 2:1 hay to concentrate diet for 20 days before starting and throughout the experimental period. The diet included grass-legume hay and a concentrate mixture (0.515 barley grain, 0.16 corn grain, 0.14 wheat bran, 0.125 sunflower meal, 0.04 soybean meal, 0.02 minerals). The hay was obtained from the second cut of a temporary grassland, composed of Festuca pratense, Dactilis glomerata, Medicago sativa and Trifolium repens. It presented a 3:1 grass to legume ratio and crude protein (CP) and neutral detergent fibre (NDF) contents (of DM) of 14.8 and $55.7 \%$, respectively. The diet provided $15.4 \%$ of CP (of DM) and was offered at an intake level of $40 \mathrm{~g} \mathrm{DM} \cdot \mathrm{kg}^{-1} \mathrm{LW}{ }^{0.75}$ in two equal portions at 8 and $16 \mathrm{~h}$.

\subsection{Ruminal incubation and degradability}

Bags of $11 \times 7 \mathrm{~cm}$ (inner dimensions) were made by heat-sealing (Preci-Pack P30N, Dover Pack S.A., Barcelona, Spain) from nylon blutex cloth with a pore size of $46 \mu \mathrm{m}$ (Reference 120T, Tissages Tissues Techniques, Villeneuve la Garenne, France). The bags were filled with approximately $3 \mathrm{~g}$ (air-dry basis) of feed samples and incubated in the rumen of each animal for intervals of $2,4,8,16,24,48$ and $72 \mathrm{~h}$. The specifications of the bags and incubations agree with those of the Inra standard method [15]. Two series of incubations with duplicate bags were conducted for each feed. At each series of incubation, all bags were placed simultaneously in the rumen just before the sheep were offered their first meal of the morning. After collecting bags from the rumen, they were washed with tap water, three times for $5 \mathrm{~min}$, in a turbine washing machine. For each sheep and incubation time, one bag of each incubation series was dried for $48 \mathrm{~h}$ at $80^{\circ} \mathrm{C}$ in a forced air oven and analysed for DM and nitrogen. The other bag was stored at $-20{ }^{\circ} \mathrm{C}$, freeze-dried and used for intestinal digestibility studies.

The evolution of nitrogen disappearance $(p)$ with an incubation time $(t)$ was described for each animal using the model proposed by Ørskov and McDonald [17]:

$$
p=a+b\left(1-\mathrm{e}^{k} d^{t}\right)
$$


In this model, the constant $a$ represents the soluble or very fast degradable fraction and $b$ represents the non-soluble degradable component, which disappears at a constant fractional rate $k_{d}$ per unit of time. The fraction of undegradable nitrogen $(r)$ was estimated as $1-(a+b)$.

The rumen outflow rate $\left(k_{p}\right)$ used to estimate degradability values was determined by supplying a pulse dose $(50 \mathrm{~g})$ of labelled sunflower meal SD2 (the same as that included in the concentrate) immediately before the first morning meal in the stall of each animal. Previously, this meal was washed with a commereial detergent in an automatic washing machine to eliminate the soluble components and labelled with ytterbium. Labelling was carried out by immersion for $24 \mathrm{~h}$ as described by Gonzalez et al. [10] using a dose of $20 \mathrm{mg} \mathrm{Yb} \cdot \mathrm{g}^{-1}$ of feed. A total of 18 samples of faeces for each animal was taken from the rectum, the first before supplying the marker and the rest at intervals of 4,6 and $12 \mathrm{~h}$ during the periods of $12-36,36-72$ and $72-120 \mathrm{~h}$ postdosage, respectively. These samples were dried, milled and analysed for ytterbium. The evolution of ytterbium concentrations in the faeces with time was fitted with the model proposed by Grovum and Williams [11] and the rate constants derived from the decreasing phase of concentrations were used as $k_{p}$ values for all the meals tested. Effective degradability $(P)$ was estimated according to Ørskov and McDonald [17] as:

$$
P=a+\frac{b k_{d}}{k_{d}+k_{p}}
$$

\subsection{Intestinal digestibility}

The freeze-dried residues obtained from ruminal incubations for each tested feed and incubation time were pooled and resulting samples were analysed for DM and nitrogen. After pooling, six subsamples of $0.2 \mathrm{~g}$ were taken and placed in heat-sealed nylon bags of the above-indicated material having an approximately round shape (diameter $3 \mathrm{~cm}$ ). A total of 45 bags, two bags from each feed and for each rumen incubation time and three additional empty bags (used as blanks), was inserted using a spindle through the duodenal cannula into the small intestine of each animal. Nine bags were inserted at random per sheep per day at a rate of one bag every $15 \mathrm{~min}$. Once recovered from the faeces, the bags were mechanically washed, as indicated for the bags incubated in the rumen, and then destined, intact, to nitrogen analysis. Blanks containing a known weight of nylon were used to correct for nitrogen content. The disappearance in the intestines of undegraded nitrogen was calculated as the amount of nitrogen lost from the bag divided by the amount of nitrogen in the bag before the intestinal passage. The undigested nitrogen content was calculated as the percentage of nitrogen of the original sample remaining in the bags after ruminal incubation and intestinal passage.

\subsection{Chemical analyses}

Samples of tested feeds were analysed for $\mathrm{DM}$, ash, CP (Nkjeldahl $\times 6.25)$ and ether extract by AOAC methods [2] and for NDF, acid detergent fibre (ADF) and acid detergent lignin (ADL) according to the Robertson and Van Soest procedures [20]. In tested feeds, the NDF residues were used for the analyses of neutral detergent insoluble nitrogen (NDIN) and the ADF analyses were made directly and in two duplicate series for the subsequent determination of ADL and acid detergent insoluble nitrogen (ADIN), respectively. Rumen incubation residues and intestinal mobile nylon bags were analysed for nitrogen by the Kjeldahl method. Samples of faeces collected for transit studies were incinerated at $550{ }^{\circ} \mathrm{C}$ and then boiled with a solution of $1.5 \mathrm{M} \mathrm{HNO}_{3}$ and $\mathrm{KCl}\left(3.81 \mathrm{~g} \cdot \mathrm{L}^{-1}\right)$. The resultant solutions were analysed for ytterbium by atomic absorption spectrometry (Smith-Hieftje 22, Thermo Jarrell Ash Corp. Massachusetts, USA) including, in the standards, the predosed sample of faeces (in equal weight to that employed in problem samples) to avoid interferences of the mineral matrix.

\subsection{Statistical methods}

The different kinetics associated with the indicated models were fitted using a non-linear regression programme. Statistical analysis of the degradation parameters and effective degradability of nitrogen in the rumen were made by variance analysis with animals and meals as factors in the model. A split-plot design with meals as whole plots and times of incubation as subplots was used to conduct the variance analyses of intestinal digestibility of nitrogen and undigested nitrogen contents. In all cases, orthogonal contrasts were made between SD1 and SD2 and between the mean of these samples and sample $W$. The effect of ruminal incubation time on ID was established by an exponential equation (3) (see Results) and by linear and quadratic effects for undigested nitrogen. 
Table II. Rumen degradation parameters and effective rumen degradability of nitrogen of sunflower meals.

\begin{tabular}{|c|c|c|c|c|c|c|c|}
\hline & \multicolumn{4}{|c|}{ Meals } & \multicolumn{3}{|c|}{ Porbablility and orthogonal contras } \\
\hline & $\mathrm{SD}_{1}$ & $\mathrm{SD}_{2}$ & W & $\mathrm{SE}$ & $P$ & $\begin{array}{c}\mathrm{SD}_{1} \\
\text { versus } \mathrm{SD}_{2}\end{array}$ & $\begin{array}{l}\mathrm{SD}_{1}, \mathrm{SD}_{2} \\
\text { versus W }\end{array}$ \\
\hline Undegradable fraction $(r)$ & 0.037 & 0.044 & 0.072 & 0.007 & 0.043 & 0.516 & 0.018 \\
\hline Soluble fraction $(a)$ & 0.365 & 0.238 & 0.206 & 0.029 & 0.038 & 0.038 & 0.057 \\
\hline Potentially degragradable & & & & & & & \\
\hline fraction $(b)$ & 0.598 & 0.718 & 0.722 & 0.027 & 0.052 & 0.035 & 0.126 \\
\hline Degradation rate $\left(k_{\mathrm{d}}, \% \cdot \mathrm{h}^{-1}\right)$ & 15.1 & 15.2 & 4.2 & 1.35 & 0.007 & 0.987 & 0.003 \\
\hline Effective degradability $(P)$ & 0.812 & 0.776 & 0.537 & 0.007 & $<0.001$ & 0.019 & $<0.001$ \\
\hline
\end{tabular}

SE: standard error of the mean.

\section{RESULTS AND DISCUSSION}

\subsection{Ruminal degradation}

The parameters of degradation kinetics and effective degradability of nitrogen in the rumen are shown in table II. The average and the standard error of the mean (SE) of $k_{p}$ values used to establish the effective degradability estimates were $4.99 \pm 0.20\left(\% \cdot \mathrm{h}^{-1}\right)$. The potential extent of nitrogen degradation of SD1 and SD2 meals was the same, as is shown by their similar undegradable fractions $(0.037$ and 0.044 , respectively). Nevertheless, there were important differences in their availabilities with time. Therefore, the greater $(P=0.038)$ soluble fraction observed for SD1 $(0.365$ versus 0.238 for SD2) is associated with a compensatory reduction $(P=0.035)$ in the potentially degradable fraction $(0.598$ versus 0.718 , respectively). Consequently, this meal showed a greater value of effective degradability $(0.812$ versus $0.776 ; P=0.019)$, since there was not any difference in the degradation rate. The undegradable fraction $(0.072)$ and the degradation rate $\left(4.2 \% \cdot \mathrm{h}^{-1}\right)$ were respectively higher $(P=0.018)$ and lower $(P=0.003)$ in meal $\mathrm{W}$ compared to the other meals. Both differences, but mainly the latter, were responsible for the lowest
$(P<0.001)$ effective degradability $(0.537)$ observed for this meal.

The differences in the degradation parameters could be explained by differences in the industrial obtention procedures and in the chemical composition of the samples. Therefore, the high content of undegradable nitrogen of meal W may be related to its considerably high content of fibrous constituents and to the high proportion of nitrogen bound to these fractions (table I). On the contrary, the low degradation rate and effective degradability found for this meal may be mainly related to the long period of time between the pressure and solvent extraction process during which the meal was exposed to high temperatures. Thus, this meal would have similar characteristics to expeller meals. Broderick and Craig [6] suggested that heat decreases ruminal nitrogen degradation by partially blocking reactive sites for microbial proteolytic enzymes and by partially reducing protein solubility. Therefore, the pressure process has a greater influence on the reduction of ruminal degradation of nitrogen than the solvent extraction process $[5,9]$. The low degradation rate observed for this meal is very similar to that of a sunflower meal treated with formaldehyde [8], which gives additional evidence of protection by heat. 
On the contrary, effective degradabilities of conventional solvent-extracted meals (SD1, $\mathrm{SD} 2)$ agree with previous results $[8,14,16$, 24].

\subsection{Intestinal digestibility and mathematical model of calculation}

The effect of the ruminal incubation time on ID of undegraded nitrogen is shown in table III. Residues of ruminal incubation of meal SD2 for the time period of $16 \mathrm{~h}$ were contingently lost and consequently intestinal digestibility was not determined. The variance analysis of these data shows effects $(P<0.001)$ for ruminal incubation time, meals and the interaction meal $\times$ incubation time. This interaction is basically due to the different evolution of the disappearance of nitrogen from mobile bags with conventional meals (SD1, SD2) compared to that with meal $\mathrm{W}$. Therefore, SD1 and SD2 meals showed a more rapid decrease with increasing rumen incubation times than meal
W. Average values for SD1 (0.683) and SD2 $(0.661)$ were similar $(P=0.158)$ and lower $(P<0.001)$ than those obtained for $\mathrm{W}(0.672$ versus 0.821 ).

The evolution of ID values for $24 \mathrm{~h}$ (samples SD1 and SD2) or $48 \mathrm{~h}$ (sample W) of rumen incubation time fitted well to an exponential curve:

$$
\mathrm{ID}=s+h \mathrm{e}^{-k_{i} t}
$$

These periods are long enough in practical terms for us to consider the extent of the degradation effects in the rumen; thus, considering the disappearance from the rumen by degradation as well as by transit, the potentially degradable nitrogen which remained in the rumen represented only 0.47 and $0.57 \%$ of total nitrogen in the feed for $\mathrm{SD} 1$ and SD2 at $24 \mathrm{~h}$ and $0.86 \%$ for $\mathrm{W}$ at $48 \mathrm{~h}$.

Values of ID corresponding to enlarged rumen incubation times, and therefore with degradation values close to the potential degradation extent, showed deviation from

Table III. Effects of ruminal incubation time on intestinal digestibility of undegraded nitrogen and on undigested nitrogen in the whole digestive tract (percentage of the original nitrogen) of different sunflower meals.

\begin{tabular}{|c|c|c|c|c|c|c|}
\hline \multirow{2}{*}{$\begin{array}{l}\text { Rumen incubation } \\
\text { time (h) }\end{array}$} & \multicolumn{3}{|c|}{ Intestinal digestibility } & \multicolumn{3}{|c|}{ Undigested nitrogen } \\
\hline & SD1 & SD2 & W & $\mathrm{SDl}^{\mathrm{a}}$ & $\mathrm{SD} 2^{\mathrm{a}}$ & $W^{b}$ \\
\hline 2 & 0.881 & 0.848 & 0.866 & 5.64 & 8.89 & 9.94 \\
\hline 4 & 0.810 & 0.793 & 0.850 & 6.72 & 8.62 & 9.97 \\
\hline 8 & 0.747 & 0.686 & 0.842 & 5.47 & 8.45 & 9.31 \\
\hline 16 & 0.706 & - & 0.834 & 2.66 & - & 7.25 \\
\hline 24 & 0.709 & 0.657 & 0.828 & 2.02 & 2.66 & 6.37 \\
\hline 48 & 0.467 & 0.489 & 0.802 & 1.59 & 1.91 & 2.01 \\
\hline 72 & 0.461 & 0.496 & 0.725 & 1.59 & 1.86 & 1.95 \\
\hline Principal effects & meal & inc. time & meal $\times$ inc. time & meal & inc. time & meal $\times$ inc. time \\
\hline SE & 0.009 & 0.014 & 0.024 & 0.210 & 0.320 & 0.542 \\
\hline $\mathrm{P}$ & $<0.001^{\mathrm{c}}$ & $<0.001$ & $<0.001$ & $0.004^{\mathrm{d}}$ & $<0.001$ & $<0.001$ \\
\hline
\end{tabular}

SE: standard error of the mean.

${ }^{a}$ linear $(P<0.001)$ and quadratic $(P<0.001)$ effects with ruminal incubation time; ${ }^{\mathrm{b}}$ linear $(P<0.001)$ and quadratic $(P<0.01)$ effects with ruminal incubation time; ${ }^{c}$ probability of orthogonal contrasts: SD1 versus SD2: 0.158 ; SD1, SD2 versus $W:<0.001$; $^{d}$ probability of orthogonal constrasts: SD1 versus SD2: $0.017 ;$ SD1, SD2 versus W: 0.002 . 
the general tendency described by the exponential curves. These deviations could be explained by considering that in these residues digestible nitrogen was mainly derived from microbial contamination. Likewise, this hypothesis allows us to explain that this fraction which was indigestible at the ruminal level could be digested in a high proportion in the intestine. Ruminal microbial contamination of sunflower meal should be high. Thus, using diaminopimelic acid as a bacterial marker, Alexandrov [1] observed that $42 \%$ of undegraded nitrogen after $48 \mathrm{~h}$ of incubation were of microbial origin.

The equations obtained using mean values for each animal and each ruminal incubation time were:

$$
\begin{gathered}
\text { SD1: ID }=0.699( \pm 0.0131)+0.253 \\
( \pm 0.0186) \mathrm{e}^{-0.186( \pm 0.034) t} \\
n=15 ; \mathrm{RSD}=0.0249 \\
\mathrm{SD} 2: \mathrm{ID}=0.647( \pm 0.0163)+0.287 \\
( \pm 0.0217) \mathrm{e}^{-0.195( \pm 0.033) t} \\
n=12 ; \mathrm{RSD}=0.0265 \\
\mathrm{~W}: \mathrm{ID}=0.795( \pm 0.0434)+0.0763 \\
( \pm 0.0389) \mathrm{e}^{-0.046( \pm 0.060) t} \\
n=18 ; \mathrm{RSD}=0.0339
\end{gathered}
$$

The decrease in the ID of undegraded nitrogen obtained with increasing rumen incubation times indicated the progressive enrichment in undigestible nitrogen compounds of feed particles as a consequence of the extent of rumen degradation. The importance of this effect in each meal was, however, different. Therefore, the low fractional rate $k_{i}$ observed for meal W, (approximately four times lower than for the other meals) could be the consequence of its very low ruminal degradation rate $\left(k_{d}\right.$, table $\left.I\right)$, that would produce a slow and relatively low enrichment in undigestible nitrogen compounds. In this way, the characteristics of rumen degradation kinetics, and especially the magnitude of $k_{d}$ would produce an important effect on the evolution of ID. In addition, feed NDIN and ADIN contents could also have an important effect as discussed below.
The utilisation of an exponential equation (3) to describe the evolution of the ID of undegraded residues allows for the estimation of the effective intestinal digestibility from this function and from the post-ruminal flow of undegraded nitrogen $\left(U_{t}\right)$. This last function can be established considering that undegraded nitrogen is defined by $u=r$ $+b \mathrm{e}^{-k} d^{t}$ and that the rumen outflow of any feed constituent is defined by $f=1-\mathrm{e}^{-k_{p} t}$. Thus, the corrected outflow rate from the rumen of undegraded nitrogen is $u(\mathrm{~d} f / \mathrm{d} t)$ and its cumulative proportion up to time $t$ $\left(U_{t}\right)$ can be calculated from:

$$
\begin{aligned}
& U_{t} \mathrm{~d} t=\int_{0}^{t} u \frac{\mathrm{d} f}{\mathrm{~d} t} \mathrm{~d} t=\int_{0}^{t}\left(r+b \mathrm{e}^{-k} d^{t}\right) k_{p} \mathrm{e}^{-k_{p} t} \mathrm{~d} t= \\
& r\left(1-\mathrm{e}^{-k_{p} t}\right)+\frac{b k_{p}}{k_{d}+k_{p}}\left(1-\mathrm{e}^{-\left(k_{d}+k_{p}\right) t}\right)
\end{aligned}
$$

As time from feeding increases, the fraction of undegraded nitrogen leaving the rumen $(u)$ falls to zero, as does the rate of passage $(\mathrm{d} f / \mathrm{d} t)$, and so the proportion of undegraded nitrogen approaches closer and closer to the final value:

$$
U=r+\frac{b k_{p}}{k_{d}+k_{p}}
$$

Likewise, the corrected rate of digested nitrogen in the intestine is $\mathrm{ID}(\mathrm{d} U / \mathrm{d} t)$, which, in accord with equation (4), is equivalent to ID $u(\mathrm{~d} f / \mathrm{d} t)$, and their cumulative proportion up to time $t\left(D_{i(t)}\right)$ can be derived from:

$$
\begin{gathered}
D_{i(t)}=\int_{0}^{t} \mathrm{ID} u \quad \frac{\mathrm{d} f}{\mathrm{~d} t} \mathrm{~d} t=\int_{0}^{t}\left(s+h \mathrm{e}^{-k_{i} t}\right) \\
\left(r+b \mathrm{e}^{-k_{d} t}\right) \mathrm{k}_{p} \mathrm{e}^{-k_{p} t} \mathrm{~d} t=s\left(r\left(1-\mathrm{e}^{-k_{p} t}\right)+\frac{b k_{p}}{k_{d}+k_{p}}\right. \\
\left.\left(1-\mathrm{e}^{-\left(k_{d}+k_{p}\right) t}\right)\right)+h k_{p}\left(\frac{r}{k_{p}+k_{i}}\left(1-\mathrm{e}^{-\left(k_{p}+k_{i}\right) t}\right)+\right. \\
\left.\frac{b}{k_{d}+k_{p}+k_{i}}\left(1-\mathrm{e}^{-\left(k_{d}+k_{p}+k_{i}\right) t}\right)\right)
\end{gathered}
$$

As indicated above, as the time from feeding increases, the fraction of nitrogen flowing into the intestine tends to zero, so that the proportion of nitrogen from the feed digested in the intestines tends to: 
$D_{i}=s\left(r+\frac{b k_{p}}{k_{d}+k_{p}}+h k_{p}\left(\frac{r}{k_{p}+k_{i}}+\frac{b}{k_{d}+k_{p}+k_{i}}\right)\right.$

From this value, the effective intestinal digestibility of undegraded nitrogen (EID) can be obtained as:

$$
\mathrm{EID}=\frac{D_{i}}{U}
$$

This proposed method allows practical estimations of intestinal digestibility to be obtained for those feeds showing variations of this parameter with the rumen incubation time. The first step in the development of this model, that is the determination of the ruminal outflow of undegraded nitrogen, is analogous to that proposed by Ørskov and McDonald [17] for the calculation of nitrogen degradability in the rumen. Therefore, equation (5), which describes the accumulative outflow, is mathematically complementary to equation (2) obtained by these authors for the estimation of degradability. This method, based on solutions by integration, remains valid irrespective of the form of the functions employed ( $u, f$ and ID), because there is the possibility of obtaining, in the case of the variation of any of them, revised expressions to replace equation (7) for the estimation of the proportion of nitrogen from the feed digested in the gut.

The estimates by the proposed method of the EID of undegraded nitrogen and of the percentage of nitrogen from the feed digested or undigested in the gut are shown in table $I V$. The values of EID, ranging from 0.767 to 0.844 were close to the value of 0.85 determined for sunflower meals by the method used in the PDI system [24]. The results obtained also showed that ID of undegraded nitrogen could differ between samples of the same class of feeds (tables III and $I V$ ), so it would not be considered as a constant value as already indicated [13]. The highest values of ID observed in meal W showed a possible positive effect of the obtention process, because it did not only
Table IV. Intestinal utilisation of nitrogen of different sunflower meals.

\begin{tabular}{lrrr}
\hline & \multicolumn{3}{c}{ Meals } \\
\cline { 2 - 4 } & SD1 & SD2 & W \\
\hline $\begin{array}{l}\text { Effective intestinal } \\
\text { digestibility (EID) }\end{array}$ & 0.804 & 0.767 & 0.844 \\
$\begin{array}{l}\text { Digestible undegraded } \\
\text { nitrogen }\left(\mathrm{D}_{\mathrm{i}}\right)^{\mathrm{a}}\end{array}$ & 15.1 & 17.2 & 39.0 \\
Undigested nitrogen & 3.7 & 5.2 & 7.3 \\
\hline
\end{tabular}

a Percentage of original nitrogen.

increase the concentration of the rumen bypass protein, but also resulted in a high value for its ID and, therefore, a higher nitrogen value of the feed. These results agree with those of Stern et al. [21] who, for four diets that included soybean meal or whole soybeans with different treatments, observed an increase of in vivo nitrogen intestinal digestibility of the diet with a reduction of the ruminal nitrogen degradability of the soya source. In a study with brewer grains dried at different temperatures, Pereira et al. [18] also observed an increase in the amount of digestible bypass nitrogen associated with a reduction of ruminal nitrogen degradability with the heat treatment intensity.

The effect of the ruminal incubation time on the undigested nitrogen contents after ruminal and intestinal incubations is also shown in table III. The variance analysis of these data shows effects for meals $(P=0.004)$, ruminal incubation time $(P<0.001)$, and the interaction meal $\times$ incubation time $(P<0.001)$. The undigested nitrogen contents decreased in a linear and quadratic form in all tested feeds with increased rumen incubation times. The average value for W $(6.69 \%)$ was higher $(P=0.002)$ than those of conventional meals ( $4.53 \%$ on average), and amongst these, SD1 presented a lower value than SD2 (3.67 versus $5.40 \%, P=0.017$ ). 
The decrease in undigested nitrogen values after ruminal and intestinal digestion observed in all meals with increasing ruminal incubation times should be related to the progressive microbial degradation of components inhibiting the enzymatic digestion of protein in the small intestine such as nitrogen compounds bound to the cell wall. Moreover, it may be noted that the ranking of the obtained undigested nitrogen values is in relation to the NDIN and ADIN contents of meals. The progressive ruminal degradative actions on these components also influence gut digestibility values, underlining the importance of considering the effect of rumen microbial actions in the estimation of intestinal digestibility. Thus, the determination of intestinal digestibilities of undegraded nitrogen based on estimations with nylon bags made on the original feed as proposed by Helplund et al. [13] can lead to errors.

Although effective values of undigested nitrogen (table $I V$ ) are slightly higher than the feed content of ADIN, the values of undigested nitrogen corresponding to high ruminal incubation times are lower than these contents. With the exception of a possible subestimation by considering the disappearance from the bag as degradation or digestion, these results tend to show that ADIN could be degraded to a certain extent in the rumen. Part of the artificial ADIN resulting from Maillard reaction products may be degraded in the rumen [27]. In addition, Aufrere et al. [3] showed a partial ruminal degradation of ADIN in feeds not sujected to thermal treatment, such as green or ensiled alfalfa.

\section{CONCLUSIONS}

The extent and duration of microbial actions in the rumen are primary factors in determining the ID of undegraded protein. The method proposed here for calculating this digestibility combines both the estimations of degradation and passage rate in the rumen with data from mobile bags, which then represent a combination of the different digestive occurrences. This method, based on solutions by integration, spares the problems derived from the use of a fixed but arbitrary time for ruminal preincubation and it can be used as a screening method for testing a large number of feeds and for the study of the factors that determine ID in ruminants.

\section{REFERENCES}

[1] Alexandrov A.N., Effect of ruminal exposure and subsequent microbial contamination on dry matter and protein degradability of various feedstuffs, Anim. Feed Sci. Technol. 71 (1998) 99-107.

[2] AOAC, Official Method of Analysis, 14th ed., Association of Official Agricultural Chemist, Washington, D.C., 1984.

[3] Aufrère J., Boulberhane D., Graviou D., Dégradation en sachets de nylon dans le rumen, de l'azote lié au NDF et à l'ADF d'une même luzerne, soit verte soit ensilée, in: $8^{\text {èmes Journées }}$ des Recherches sur l'Alimentation et la Nutrition des Herbivores, Paris, 1993, p. 68.

[4] Beckers Y., Théwis A., Maudoux B., Intestinal digestibility of rumen undegraded $\mathrm{N}$ of concentrates measured by the mobile nylon bag technique, Anim. Feed Sci. Technol. 61 (1996) 305-323.

[5] Broderick G.A., Relative value of solvent and expeller soybeanmeal for lactating dairy cows, J. Dairy Sci. 69 (1986) 2948-2958.

[6] Broderick G.A., Craig W., Effect of heat treatment on ruminal degradation and escape, and intestinal digestibility of cottonseed meal protein, J. Nutr. 110 (1980) 2381-2389.

[7] De Boer G., Murphy J.J., Kennelly J.J., Mobile nylon bag for estimating intestinal availability of rumen undegradable protein, J. Dairy Sci. 70 (1987) 977-982.

[8] Freer M., Dove H., Rumen degradation of protein in sunflower meal, rapeseed meal and lupin seed, placed in nylon bags, Anim. Feed Sci. Technol. 11 (1984) 87-101.

[9] Goetsch A.L., Owens F.N., The effects of commercial + processing method of cottonseed meal on site and extent of digestion in cattle, J. Anim. Sci, 60 (1985) 803-813.

[10] Gonzalez J., Rodríguez C.A., Andrés S.G., Alvir M.R., Rumen degradability and microbial contamination of fish meal and meat measured by the in situ technique, Anim. Feed Sci. Technol. 73 (1998) 71-84 
[11] Grovum W.L., Williams V.J., Rate of passage of digesta in sheep. 4. Passage of marker through the alimentary tract and the biological relevance of rate-constants derived from the changes in concentration of marker in faeces, Br. J. Nutr. 30 (1973) 313-329.

[12] Hvelplund T., Digestibility of rumen microbial protein and undegraded dietary protein estimated in the small intestine of sheep and by in sacco procedure, Acta Agric. Scand. Suppl. 25 (1985) 132-144.

[13] Hvelplund T., Weisbjerg M.R., Andersen L.S., Estimation of the true digestibility of rumen undegraded dietary protein in the small intestine of ruminants by the mobile bag technique, Acta Agric. Scand, 42 (1992) 34-39.

[14] Madsen J., Hvelplund T., Values of feed protein degradability and possible methods for its estimation in routine laboratories, in: Jarrige R., Alderman G. (Eds.), Agriculture. Feed Evaluation and Protein Requirement Systems for Ruminants, EUR, Luxembourg, 1987, pp. 97-110.

[15] Michalet-Doreau B., Vérité R., Chapoutot P., Méthodologie de mesure de la dégradabilité in sacco de l'azote des aliments dans le rumen, Bull. Tech. C.R.Z.V. Theix Inra 69 (1987) 5-7.

[16] National Research Council, Nutrients Requirements of Dairy Cattle, 6th ed., National Academy Press, Washington D.C., 1988.

[17] Ørskov E.R., McDonald I., The estimation of protein degradability in the rumen from incubation measurements weighted according to rate of passage, J. Agric. Sci. 92 (1979) 499-503.

[18] Pereira J.C., Carro M.D., González J., Alvir María R., Rodriguez C.A., Rumen degradability and intestinal digestibility of brewers' grains as affected by origen and heat treatment and of barley roolets, Anim. Feed Sci. Technol. 74 (1998) 107-121.

[19] Rae R.C., Smithard R.R., Estimation of true nitrogen digestibility in cattle by a modified nylon bag technique, Proc. Nutr. Soc. 44 (1985) $116 \mathrm{~A}$.
[20] Robertson J.B.,Van Soest P.J., The detergent system of analysis and its application to human foods, in: James W.P.T., Theander O. (Eds.), The Analysis of Dietary Fibre in Food, Marcel Dekker, New York, 1981, pp. 123-158.

[21] Stern M.D., Santos K.A., Satter L.D., Protein degradation in rumen and amino acid absorption in small intestine of lactating dairy cattle feed heat-treated whole soybeans, J. Dairy Sci. 68 (1985) 45-56.

[22] Todorov N.A., Girginov D.G., Comparison of the infusion method, mobile bag technique and in vitro method for determination of the true protein digestibility in small intestine of cattle, in: Proc. 6th Int. Symp. Protein Metabolism and Nutrition, Herning, Denmark, 1991, pp. 80-83.

[23] Vanhatalo A., Aronen I., Varvikko T., Intestinal nitrogen digestibility of heat-moisture treated rapeseed meals as assessed by the mobile-bag method in cows, Anim. Feed Sci. Technol. 55 (1995) 139-152

[24] Vérité T., Chapoutot P., Michalet-Doreau B., Peyraud J.L., Poncet C., Révision du système des protéines digestibles dans l'intestin (PDI), Bull. Techn. CRZV, Theix, Inra 70 (1987) 19-34.

[25] Voigt J., Piatkowski B., Engelmann H., Rudolph E, Measurement of the postruminal digestibility of crude protein by the bag technique in cows, Archiv für Tierernährung 35 (1985) 555-562.

[26] Volden H., Harstad O.M., Effect of rumen incubation on the true indigestibility of feed protein in the digestive tract determined by nylon bag techniques, Acta Agric. Scand. 45 (1995) 106-115.

[27] Waters C.J., Kitcherside M.A., Webster A.J.F., Problems associated with estimating the digestibility of undegraded dietary nitrogen from acid-detergent insoluble nitrogen, Anim. Feed Sci.Technol. 39 (1992) 279-291.

[28] Yang W.Z., Poncet C., Mesure de la digestion de l'azote alimentaire dans les differentes parties du tube digestif du mouton par la technique des sachets de Nylon, Reprod. Nutr. Dev. 28 (suppl.1) (1988) 125-126. 